http://dx.doi.org/10.30681/23588403v14i0109

\title{
EL CABALLERO DE OLMEDO, DE LOPE DE VEGA: CONSIDERAÇÕES SOBRE A FORTUNA CRÍTICA E OS ESTUDOS POÉTICOS E RETÓRICOS
}

Gabriel Furine CONTATORI (UNIFESP) $^{1}$

Data de recebimento: $11 / 08 / 2020$

Data de aceite: $06 / 10 / 2020$

\begin{abstract}
Resumo: Neste artigo discutimos alguns estudos que constituem a fortuna crítica da peça $E l$ caballero de Olmedo (1641), de Félix Lope de Vega y Carpio (1562 - 1635), contrapondo-os aos estudos poéticos e retóricos sobre as práticas letradas do século XVII. A fortuna crítica da peça lopesca é, em grande medida, caudatária e continuadora do estudo pioneiro de Francisco Rico, datado de 1981, que trouxe à lume as fontes que teriam sido consultadas por Lope de Vega para escrever o Caballero. O estudo de Rico e de outros pesquisadores invalida, por exemplo, o preceito, em voga no século XVII, da suspensão. Com base nos estudos poéticos e retóricos, que, ao procurarem historicizar as práticas letradas do Seiscentos, consideram a vigência da Poética e da Retórica durante o Antigo Regime, buscamos demonstrar limitações em alguns estudos que se constituíram enquanto fortuna crítica de uma das mais importantes peças do teatro lopesco.
\end{abstract}

Palavras-chave: Poética. Retórica. Fortuna crítica. Teatro. Lope de Vega.

\begin{abstract}
In this article we discuss some studies that constitute the critical fortune of the piece El caballero de Olmedo (1641), by Félix Lope de Vega y Carpio (1562-1635), opposing them to poetic and rhetorical studies on literate practices of the seventeenth century. The critical fortune of the lopesca piece is, to a large extent, the basis and continuer of Francisco Rico's pioneering study, dated 1981, which brought to light the sources that would have been consulted by Lope de Vega to write Caballero. The study of Rico and other researchers invalidates, for example, the precept, in vogue in the seventeenth century, of suspension. Based on poetic and rhetorical studies, which, while seeking to historicize the literate practices of the seventeenth century, consider the validity of Poetics and Rhetoric during the Old Regime, we seek to demonstrate limitations in some studies that were constituted as critical fortune o fone of the most importante plays of the lopesco theater.
\end{abstract}

Keywords: Poetic. Retoric. Theater. Critical fortune. Lope de Vega.

\section{Introdução}

A peça El caballero de Olmedo, de Félix Lope de Vega y Carpio (1562-1635), foi publicada, em 1641, na "Veinticuatro parte perfecta de las comedias del Fénix de España". Essa peça é tida como uma das mais representativas do teatro espanhol do século XVII (ARELLANO, 2001; ENDRESS, 2005; OLIVEIRA, 2014). Talvez, por conta disso, essa obra teatral tenha recebido, ao longo do tempo, uma considerável fortuna crítica.

\footnotetext{
${ }^{1}$ Mestrando em Estudos Literários no Programa de Pós-Graduação em Letras da Universidade Federal de São Paulo (UNIFESP), São Paulo, Brasil. E-mail: furine.contatori@unifesp.br
} 
Neste artigo, dada sua limitação física, deter-nos-emos em alguns estudos, enquanto constitutivos da fortuna crítica da peça lopesca, do final do século XX, especificamente, o estudo de Rico (2016 [1981]) e de García Valdés (1994), e outros produzidos no início do século XXI (ARELLANO, 2001; ENDRESS, 2005). Além do mais, buscamos contrapor essa fortuna crítica aos estudos poéticos e retóricos das práticas letradas do século XVII. Convém, portanto, explicar, à guisa de introdução, em que consiste os estudos poéticos e retóricos.

Os estudos poéticos e retóricos, que se orientam na perspectiva aberta por João Adolfo Hansen, procuram analisar os textos produzidos entre os séculos XVI, XVII e XVIII “a partir do exame de procedimentos previstos e aplicados pelas convenções letradas em vigência no período em questão" (PÉCORA, 2018, p. 12). Nesse ensejo, tendo em vista que a Retórica, mas também a Poética, perdurou até o século XVIII, quando começou a se "eclipsar com chamado Iluminismo" (CHIAPPETTA, 2001, p. 40), é necessário recorrer (mas não somente), por exemplo, aos preceitos antigos e modernos dessas disciplinas a fim de se compreender as produções letradas do Antigo Regime. É nesse sentido que se faz importante "historicizar", ou seja, tendo-se ciência de que os textos são contingentes e, por isso, datados historicamente, e que "quanto maior é o tempo que separa o autor e o leitor, mais difícil é a leitura, pois os critérios da invenção do texto são outros" (HANSEN, 2019, p. 36), deve-se procurar refazer, na medida do possível, os procedimentos inventivos e também da recepção que enformam os textos seiscentistas.

Ainda à título de introdução, cabe fazer um breve resumo do argumento de $E l$ caballero de Olmedo para que se possa compreender as análises que se seguirão. A peça é ambientada no reinado (1406-1454) de D. Juan II de Castilla y de León. Em passagem por Medina del Campo, D. Alonso Manrique, o cavaleiro de Olmedo, encontra, na feira, Doña Inés e por ela se apaixona. Convém lembrar que Doña Inés há mais de três anos era cortejada por D. Rodrigo. Para conseguir se aproximar da amada, D. Alonso contrata os serviços da alcoviteira Fabia, a quem entrega um bilhete de amor para ser dirigido a Inés. Inés aceita o bilhete, pois também havia notado a presença de D. Alonso na feira de Medina e por ele também tinha se apaixonado. Alonso e Inés passam a se encontrar às escondidas com a ajuda da alcoviteira Fabia e do escudeiro de Alonso, Tello. D. Rodrigo, ao descobrir sobre a relação de Inés com Alonso, trama com seu amigo, D. Fernando, matar o rival amoroso. Quando D. Alonso se dirigia de Medina a Olmedo, durante uma noite, para visitar os pais, após ter saído vitorioso de uma tourada na festa da Cruz de Mayo ocorrida em Medina, é assassinado. Tello, seu escudeiro, consegue levar o cavaleiro ferido até os pais, em Olmedo, onde expira. O escudeiro retorna a 
Medina e. após narrar o ocorrido, solicita que o rei, D. Juan II, aplique a justiça matando os homicidas. O rei atende ao pedido e ordena que sejam cortados os infames pescoços dos assassinos.

\section{O estudo de Francisco Rico e a invalidação do preceito da suspensão}

Certamente, o estudo de Francisco Rico, datado de 1981, é um dos pioneiros e mais importantes acerca da peça El caballero de Olmedo, de Lope de Vega, haja vista que diversos estudos posteriores dão continuidade as afirmações defendidos por Rico (cf. GARCÍAVALDÉS, 1994; ARELLANO, 2001; ENDRESS, 2005; OLIVEIRA, 2014). Em seu estudo, Rico (2016) identificou duas fontes, uma histórica e outra literária, que teriam sido utilizadas por Lope de Vega para a composição do Caballero.

No que se refere à fonte histórica, Rico (2016) verificou que os arquivos de Simancas (município da Espanha localizado na província de Valladolid) registram que em 6 de novembro de 1521, don Juan de Vivero, “ que volvía 'por el camino real de la villa de Medina del Campo para la dicha villa de Olmedo" (RICO, 2016, p. 34), acompanhado pelo ajudante Luis de Herrera, foi assassinado por seu vizinho Miguel Ruiz. As razões do assassinato, porém, diferem nos vários testemunhos (ARELLANO, 2001, p. 96).

No tocante à fonte literária, Rico (2016, p. 42) acredita que com o translado da corte para Valladolid, entre 1601 e 1606, impulsionou-se a curiosidade pelas coisas da capital, o que resultou na proliferação, no início do Seiscentos, das recreações artísticas da lenda do cavaleiro de Olmedo. Dentre essas diversas recreações artísticas, destaca-se a recuperação de um Baile del caballero de Olmedo, datado de 1606 (ARELLANO, 2001, p. 96). Conserva-se deste baile diversas versões, que guardam entre si uma aproximação: a utilização dos conhecidos versos da canção do cavaleiro. Tais versos são utilizados na peça El caballero de Olmedo, de Lope: “Que de noche le mataron / al Caballero, / la gala de Medina, / la flor de Olmedo”(LOPE DE VEGA, 2016, v. 2374-2377) (grifos no original).

Para Rico (2016), essas fontes, especialmente a literária, eram de conhecimento do auditório e, por essas razões, este sabia, desde o início da peça, que o cavaleiro de Olmedo, D. Alonso Manrique, seria morto no caminho de Medina a Olmedo durante uma noite. Nessa direção, Endress (2005, p. 2010) comenta: “Lo único fijo era de entrada el desenlace trágico. Conociendo este desenlace, los espectadores debían de estar curiosos por conocer la prehistoria del drama. Desde el princípio sabían más que el protagonista”. Assim sendo, a canção do 
cavaleiro em que Lope se baseia para escrever seu Caballero de Olmedo, de acordo com GarcíaValdés (1994, p. 151), "resulta factor esencial en el desenlace de la tragedia".

É evidente em diversos momentos da peça "anúncios" da morte do cavaleiro e, inclusive, menção às fontes utilizadas. No que se refere ao primeiro aspecto, convém citar alguns excertos da peça. No primeiro ato, Alonso, após a demora no retorno de Fabia, que havia se dirigido à casa Inés para entregar o bilhete amoroso do cavaleiro, acredita que Inés rejeitou sua carta, pois não o ama. Com isso, Alonso pede que Tello prepare os cavalos para irem para Olmedo. O escudeiro, então, alerta-o: “ALONSO: [...] y ensilla, Tello, que a Olmedo / nos hemos de ir esta tarde. / TELLO: ¿Cómo, si anochece ya?” (LOPE DE VEGA, 2016, v. 557559). Na sequência, após Fabia entregar um bilhete de Inés para Alonso, este percebe que o amor é recíproco, e decide ficar em Medina. Tello, de modo irônico, avisa aos cavalos que eles se acalmem, porque não precisarão cavalgar até Olmedo: "TELLO: Ya desta suerte / no hay que ensillar para Olmedo. / ¿Oyen, señores rocines? / Sosiéguense, que en Medina / nos quedamos" (LOPE DE VEGA, 2016, v. 571-577). A canção do cavaleiro, como já citado, relembra que o cavaleiro é morto numa noite durante a travessia de Medina a Olmedo. Assim sendo, quando Alonso decide ir de Medina a Olmedo, Tello relembra que "anochece ya". A noite é um prenúncio da morte.

No final do primeiro ato, Fabia alude à morte de Alonso por meio de dois recursos: a) a comparação de Alonso com Adônis $^{2}$ e a entoação dos dois últimos versos da canção do cavaleiro, mote da peça e de conhecimento do auditório: "FABIA: [Alonso] con galas parece Adonis... / (¡Mejor fin le den los cielos!) / [...] / Don Alonso ha de ser tuyo [Inés]; / que serás dichosa, espero, / con hombre que es en Castilla / la gala de Medina, / la flor de Olmedo" (LOPE DE VEGA, 2016, v. 883-887) (grifo no original).

No que toca ao segundo aspecto, Ryngaert (1996, p. 54) comenta que "na prática dramatúrgica dos antigos como na do século XVII, os autores com frequência fazem alusão às

\footnotetext{
2 "El mito de Adonis es una leyenda siria a la que ya Hesiodo hace alusion. Su forma mas generalmente admitida es la siguiente; el rey de Siria, Tias, tenía una hija, Mirra o Esmirna, a quien la cólera de Afrodita impulso a desear un incesto con su padre. Ayudada por su nodriza Hipolita, logró engañar a Tias, uniéndose con el durante doce noches ; pero a la duodécima, el padre se dio cuenta de la estratagema de su hija y, armado de su cuchillo, la persiguió para darle muerte. Ante el peligro, Mirra invocó la protección de los dioses, los cuales la transformaron en árbol: el árbol de la mirra. Diez meses después, la corteza de este árbol se levantó, rompiéndose y dando salida a un niño, que recibió el nombre de Adonis. Afrodita, enternecida por la belleza de la criatura, la recogió y la confio en secreto a Persefone para que la criara. Pero esta se prendo a su vez del niño, y se negó a devolverlo a Afrodita. La disputa entre las dos diosas fue zanjada por Zeus - según otros, por la musa Calíope, en su nombre - , decidiéndose que Adonis viviría un tercio del año con Afrodita, otro, con Persefone, y el tercero, donde le pluguiera. Pero Adonis pasaba siempre las dos terceras partes del ano junto a Afrodita, y sólo una al lado de Persefone. Mas tarde, sin que se sepa a ciencia cierta por que motivos, la cólera de Artemis lanzó contra el un jabalí que, durante una cacería, lo hirió mortalmente" (GRIMAL, 1979, p. 7).
} 
suas fontes, a um material histórico à disposição de todos e no qual eles se inspiram livremente". Dessa maneira, próximo ao final do ato terceiro da peça, Don Alonso, enfim, caminha para a morte. No funesto trajeto, ouve a canção do cavaleiro e alude às fontes da canção: “[...] Pero es canción / que por algún hombre hicieron / de Olmedo, y los de Medina / en este camino han muerto" (LOPE DE VEGA, 2016, v. 2421-2424).

Ainda que Rico (2016), Endress (2005) e García-Valdés (1994) não comentem, o basear-se em fontes é prática constitutiva da imitação e da emulação (ao menos até o século XVIII). No Tratado da Imitação, por exemplo, Dionísio de Halicarnasso afirma: “A imitação é uma atividade que, segundo determinados princípios teóricos, refunde um modelo" (DIONÍSIO DE HALICARNASSO, 1986, I, 3). Nesse ensejo, podemos dizer que as fontes em que Lope se orienta são seus modelos para a composição de El caballero de Olmedo. Contudo, como prevê a prática da emulação, não se deve ser servil a modelos. Na Arte Poética, Horácio diz que a matéria pública, ou seja, que a todos pertence, só será legítima do poeta, se este não "andar à volta no caminho trivial, aberto a todos, e tão-pouco procurarás, como servil intérprete, traduzir palavra por palavra" (HORÁCIO, 1984, v.132-133). De modo similar, na Poética, Aristóteles aponta que, embora o poeta possa se basear num repertório comum, em mitos tradicionais e conhecidos, não deveria ser fiel a eles, dado que "o poeta deve ser mais fabulador que versificador; porque ele é poeta pela imitação e porque imita ações" (ARISTÓTELES, 1984, 1451b 27-28).

Nas preceptivas espanholas do século XVII, os apontamentos são similares. Na Philosophia antigua poética (1596), Alonso López Pinciano afirma que “(...) no se debe alterar la fábula en aquella acción que está recebida publicamente; y esto agora sea en el ñudo y agora en la soltura (...)” (PINCIANO, 1998, p. 356). E conclui dizendo: “Ansí que los episódios que ocupan de diez partes las nueve de la acción, puédelos alterar, mas la fábula (que es el argumento y brevíssima parte de la acción) no debe recebir alteración por vía alguna". (PINCIANO, 1998, p. 357). Percebemos que para Pinciano não se deve alterar a fábula na ação que é conhecida publicamente, sendo possível o poeta fingir e inventar as demais situações, justamente, para exercer seu ofício. Nesse sentido, Lope de Vega deveria manter a morte do cavaleiro, pois era de conhecimento da audiência, mas deveria propor coisas diferentes.

Por isso, ainda que Lope de Vega deva se basear em fontes, em modelos, não deve ser servil a eles, pois, do contrário, não exerceria seu ofício de poeta. Aliás, como se sabe, a emulação pressupõe uma competição e, por conseguinte, uma superação do emulador frente ao emulado (LONGINO, 2014, p. 85-86). Com isso, o poeta deve, ao emular, procurar dar algo 
diferente à sua audiência (ROSADO FERNANDES, 1986, p. 12). Mas, pela argumentação de Rico (2016), Endress (2005) e García-Valdés (1994), o auditório, ao conhecer as fontes já conhecia o desenlace. Para eles, a morte do cavaleiro constitui o fim da peça, mesmo que, convém relembrar, a peça não termine na morte de Alonso. Com base nisso, perguntamo-nos: como Lope de Vega dá algo novo à sua audiência se todos já conheciam o desenlace da peça?

Antes de responder à questão, é pertinente comentar sobre quais fundamentos os pesquisadores acima sustentam sua argumentação. É evidente que esses estudiosos têm em vista o teatro antigo, no qual a audiência conhecia os mythos ou a fábula das peças encenadas. Nessa direção, no An Essay of Dramatic Poesy (1668), John Dryden, ao analisar o mythos/ fábula utilizado no teatro grego antigo, afirma que antes da peça chegar ao palco, já era conhecida por toda a plateia, isto porque o auditório, ao ouvir o nome de Édipo, já sabia que "he had killed his Father by mistake, and committed Incest with his Mother, before the Play; that they were now to hear of a great Plague, an Oracle, and the Ghost of Laius [...]" (DRYDEN, 1717, p. 30). Para Dryden (1717, p. 30), esse aspecto do teatro antigo é negativo porque perde-se a novidade ("Novelty being gone"), e, com a novidade, o deleite. Mais adiante em seu ensaio, o preceptista inglês afirma que o conhecimento da fábula, como ocorre no teatro antigo, faz com que o auditório perca o interesse, pois já conhece o evento (DRYDEN, 1717, p. 41).

É a fim de manter o interesse da audiência que, no século XVII, prescreve-se a utilização do preceito da suspensão. No "Discurso XLIV” da Agudeza y Arte de Ingenio (1648), Baltasar Gracián discorre sobre esse preceito nos seguintes termos:

Es gran eminencia del ingenioso artificio llevar suspensa la mente del que atende, y no luego declararse; especialmente entre grandes oradores está muy valida esta arte. Comienza a empeñarse el concepto, deslumbra la expectación, o la lleva pendiente y deseosa de ver dónde va a parar el discurso: que es un bien sutil primor; y después viene a concluir con una ponderación impensada [...] (GRACIÁN, 2004, p. 473).

Para Gracián, deve-se suspender o ânimo do auditório sem que este infira para onde será levado. O poeta/orador deve, após suspender os ânimos, dar algo impensado para a audiência. As prescrições lopescas da divisão do drama não objetivam outra coisa. No Arte de hacer comedias en este tiempo (1609), Lope de Vega afirma:

El sujeto elegido [...] / en tres actos de tiempo le reparta, [...] / Dividido en dos partes el asunto, / ponga la conexión desde el principio, / hasta que vaya declinando el paso, / pero la solución no la permita / hasta que llegue a la postrera escena; / porque, en sabiendo el vulgo el fin que tiene, / vuelve el rostro a la puerta y las espaldas / al que esperó tres horas cara a cara; / que no hay más que saber en lo que para. / [...] / En el acto primero ponga el caso, / 
en el segundo enlace los sucesos / de suerte que, hasta el medio del tercero, / apenas juzgue nadie en lo que para (LOPE DE VEGA, 2012, v. 211-212; v. 231-239, v. 298-301).

Segundo Lope de Vega, a solução não pode ser dada com antecedência, pois, se o vulgo inferir para onde será levado, virará às costas para o palco e irá embora. Os ânimos da audiência devem ficar suspensos para que ninguém julgue para onde se encaminhará. De acordo com esses apontamentos, como Lope de Vega suspende os ânimos do auditório, dando-lhe algo novo e diferente, se as fontes eram conhecidas? Para Rico (2016, p. 16-17), não há suspensão em El caballero de Olmedo:

Con el tamiz de la seguilla, digo, autor y público coincidían en el modo de mirar al Caballero: empezando por el final, por la inminencia de 'esta noche' o la seguridad de que le mataron. El griego de la edad clássica asistía a la tragedia con um cierto conocimiento prévio de la trama, y, de cualquier forma, el prólogo se encargaba de apuntalárselo sobradamente (la tragedia y el suspense tienen poco que ver, en especial si el folklore anda por medio). El espectador madrileno del Seiscientos había leído los anúncios de la función pintados con almagre -, o alguien, quizá ya en el corral, le había enterado cuando menos del título: El Caballero de Olmedo; y ya poseía el dato esencial. El Arte nuevo era tajante sobre el requisito de mantener insatisfecha la curiosidad de la audiencia por el desenlace [...]

El precepto [de la suspensión], no obstante, servía sobre todo para la comedia nuestra de cada día. Ante El caballero de Olmedo, Lope estaba perfectamente al tanto de que las gentes iban a sentarse en los bancos o a apiñarse en la cazuela sin olvidar ni por un momento 'que de noche le mataron'. Conque el proprio Fênix, con aguda percepción estética, determino hacer virtude de la necesidad y 'permitir la solución' desde las primeras escenas, avivar una y otra vez la certeza de cómo concluía El caballero de Olmedo.

Depreendemos claramente dessa extensa citação, que Rico se baseia no modelo do teatro antigo, esquecendo-se, todavia que Lope de Vega é dramaturgo do século XVII, que, ainda que emule os antigos, objetiva superá-los. No mais, o conhecimento das fontes para o pesquisador é ponto central para o desenlace da peça. Se Lope não dá nada novo, porque prescrever a suspensão? Onde fica a preceito da imitação e da emulação na constituição de $E l$ caballero de Olmedo? Na próxima seção demonstraremos que a peça de Lope assegura, sim, a suspensão. Lope, valendo-se justamente do conhecimento das fontes, fornece à sua audiência algo novo e diferente.

\section{Don Alonso Manrique: a fênix da imortalidade}


Após discorrer sobre a união do homem com o sobrenatural, Curtius (1979, p. 606) destaca a concepção da morte na Espanha do século XVII. Segundo o estudioso, na "visão do mundo da grande poesia espanhola [do século XVII], ela [a morte] não é catástrofe esmagadora, não é um fim brutal, mas uma tranquila despedida e transição" (CURTIUS, 1979, p. 606). No Caballero, D. Alonso, antes de partir, noite adentro, para aquele funesto caminho de Medina del Campo a Olmedo, no qual receberia a morte, despede-se de Inés e a ela reforça que a alma não se parte: "Yo parto, y parto a la muerte, / aunque morir no es perderte; / que si el alma no se parte, / ¿cómo es posbile dejarte, / cuanto más, volver a verte?” (LOPE DE VEGA, 2016, v. 2213-2227) (grifo no original).

Pelo menos dois aspectos podem ser destacados dessa citação. O primeiro deles é que Alonso decide caminhar para a morte. N’A Cidade de Deus, Santo Agostinho diz: "Uma coisa sei: ninguém teria morrido se não existisse para morrer um dia" (AGOSTINHO, 1996, p. 133). Assim sendo, se a morte é inevitável, é sábio aquele que, no último dia, vai "a la muerte con paso decidido", como aponta Sêneca (2005, p. 170) no De brevitate vitae. O segundo aspecto a se destacar se refere à imortalidade da alma. Em La cuna y la sepultura: para el conocimiento proprio y desengañado de las cosas agenas (1634), Francisco de Quevedo afirma que a parte principal do homem é a alma, dado que o corpo é perecível, é como um navio que foi dado ao homem para essa navegação a que chamamos vida (QUEVEDO, 1670, p. 196). E conclui:

\begin{abstract}
Empieça, pues, hombre, con este conocimiento, y ten de ti firmemente tales opiniones, que naciste para morir, y que vives muriendo; que traes el alma enterrada en el cuerpo, que quando muere, en cierta forma resucita; que tu negocio es el logro de tu alma, que el cuerpo sirve à essa vida prestada que gastas, que es tan fragil como vès; tan perecedero, como parece; y que es mas feo que parece; y que en breve tiempo lo estará mas; que tu cuidado es tu alma; y qye solas tus cosas son tuyas, y las demás agenas; que no debes trabajar en otras, sino en estas, por estar à tu cargo; que has de dar cuenta dellas al que te las dió; y que se las agradeces, solo con darsela buena, y que el premio ò el castigo se te aguarda à ti, y que pues será forçoso morir para ti, y à tu riesgo, es razon vivas para ti, y à tu provecho (QUEVEDO, 1670, p. 199).
\end{abstract}

Desse modo, quando o homem morre, apenas seu corpo (o navio) é atingido, porque a alma permanece intacta. A alma ressuscita. Por essas razões, o homem deve cuidar de sua alma, uma vez que, ao morrer e ressuscitar, prestará contas a Deus, aquele que é responsável por premiar os homens com a eternidade no Paraíso, ou castiga-los à punição eterna no Inferno.

Em El caballero de Olmedo, após a morte de D. Alonso, Tello encaminha-se à Medina e narra o acontecido ao monarca, D. Juan II, a quem pede que aplique a justiça, castigando os maus e homicidas, D. Rodrigo e D. Fernando. Tal pedido é prontamente atendido pelo rei que 
determina: "Prendedlos, / y en un teatro mañana / cortad sus infames cuellos" (LOPE DE VEGA, 2016, v. 2729-2730). Entretanto, cabe destacar, que, após descrever os acontecimentos, Tello salienta que Alonso continuará vivo, pois é fênix:

A Olmedo llegó con vida, / cuanto fue bastante, jay cielo!, / para oír la bendición / de dos miserables viejos, / que enjugaban las heridas / con lágrimas y con besos. / Cubrió de luto su casa / y su pátria, cuyo enterro / será el del fénix, Señor, / después de muerto viviendo / en las lenguas de la fama, / a quien conocen respeto / la mudanza de los hombres / y los olvidos del tiempo (LOPE DE VEGA, 2016, v. 2695-2708).

A fênix alude à imortalidade. A esse respeito, tendo em vista a historicização das práticas letradas do Seiscentos, propomos duas interpretações. A primeira, que é patente no excerto acima, diz respeito à tópica da imortalização pela fama, pela poesia. Conforme Curtius (1979, p. 507), os antigos heróis homéricos já sabiam que "a poesia dá glória eterna aos que celebra". Ademais, "os homens excelentes participam, depois da morte, de uma bem-aventura imortalidade" (CURTIUS, 1979, p. 186). No Emblematum Liber (1531), Andrea Alciato apresenta o seguinte emblema relacionado à imortalização pela poesia:

Que el nombre de los diestros es inmortal

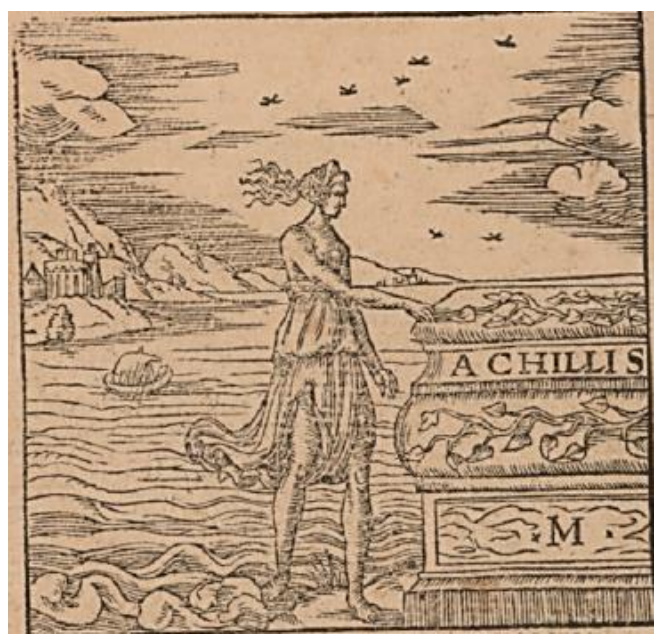

Esta es la sepultura celebrada / De Aquiles, puesta par d'el mar Sigeo. / Visitala Thetis, y cercada / Siempre la tiene de un sottil rodeo / De un verde ramo, que en ella encerrada / Està la muerte de Hector, y el deseo / De la Grecia cumplido por entero. / No deue mas à Homero que à ella Homero (ALCIATO, 1549, p. 171).

Com base nos apontamentos de Alciato, notamos que o ramo verde que está acima do túmulo de Aquiles permanece verde porque o poeta Homero imortalizou o nome do herói grego. Como demonstramos em outro artigo (CONTATORI, 2019), D. Alonso é construído como 
personagem virtuoso em oposição ao seu rival, D. Rodrigo, construído como vicioso. Devemos lembrar que o gênero epidíctico ou demonstrativo, segundo a Retórica, de Aristóteles, consiste num discurso que tem como fim o elogio das virtudes (o belo) ou a censura dos vícios (o vergonhoso) (ARISTÓTELES, 2012, I, 9, 1366a). Dessa maneira, a ressurreição de D. Alonso conferida pelas línguas da fama e pela a poesia demonstra o caráter virtuoso do personagem, digno de elogio e de emulação por parte da audiência. D. Alonso é premiado, após sua morte, com a imortalização conferida pela poesia.

A segunda interpretação possível referente à fênix, diz respeito à ressurreição da alma no Paraíso. No Sermão da Quarta-feira de Cinza, de 1672, o padre Antônio Vieira se refere, precisamente, à fênix, enquanto alegoria da imortalidade. O padre Vieira afirma que ninguém morre para estar sempre morto, e, assim, estabelece uma diferença entre duas aves, a águia e a fênix:

Morre a águia, morre a Fênix; mas a águia morta não é águia, a Fênix morta é Fênix. E por quê? A águia morta não é águia, porque foi águia, mas não há de tornar a ser águia. A Fênix morta é Fênix, porque foi Fênix e há de tornar a ser Fênix. Assim és tu que jazes nessa sepultura. Morto sim, desfeito em cinzas sim; mas em cinzas como as da Fênix. A Fênix desfeita em cinzas é Fênix, porque foi Fênix e há de tornar a ser Fênix: e tu, desfeito também em cinzas, és homem, porque foste homem e hás de tornar a ser homem. Não é a proposição, nem comparação minha, senão da Sabedoria e Verdade Eterna (VIEIRA, 2016, p. 92).

A fênix morta é fênix, pois, a partir de suas cinzas, voltará a ser fênix. O mesmo vale para os homens, que, por serem fênix, morrem para ressuscitar: "o renascer Fênix é natureza de todos. Todos nascemos para morrer e todos morremos para ressuscitar" (VIERA, 2016, p. 93). Nessa ressurreição da alma, contudo, os homens prestarão contas, como também apontara Quevedo, ao Todo-Poderoso, o qual determinará o destino das almas dos fiéis: o prêmio da bem-aventurança no Paraíso, ou o castigo no Inferno (VIEIRA, 2016, p. 48). De acordo com esses apontamentos, não seria errôneo dizer que D. Alonso recebe também, no post mortem, o prêmio da imortalidade no Paraíso. Afinal, como vimos, a alma não se parte.

Consoante ao que foi explanado até aqui, não poderíamos dizer que é justamente ao tornar D. Alonso Manrique uma fênix, pois o cavaleiro mesmo morto continua vivo, que Lope de Vega assegura o preceito da suspensão e dá algo diferente/novo à sua audiência? O auditório poderia saber que $\mathrm{D}$. Alonso morreria, mas não sabia o que aconteceria depois de sua morte. Se a morte não é o fim (ao menos para a mentalidade católica seiscentista), mas uma transição, como diz Curtius, não seria assim que Lope demonstra que não é servil intérprete de modelos? 
A morte não é o fim da peça, como o estudo de Rico (2016), Endress (2005) e García-Valdés (1994) afirmam, tampouco é o fim de D. Alonso Manrique, o cavaleiro de Olmedo. O desejo de Fabia - “¡Mejor fin le den los cielos! (LOPE DE VEGA, 2016, v. 884) - é, assim, concretizado.

No capítulo 47 da primeira parte de El ingenioso hidalgo D. Quijote de la Mancha (1605), D. Quixote enfatiza que se deve viver para a posteridade. Assim, o personagem diz que um cavaleiro "ha de ponder su nombre en el templo de la inmortalidad, para que sirve de ejemplo y dechado en los venideros siglos" (CERVANTES, 2015, p. 487). A ressurreição de D. Alonso serviria (dentre outros aspectos), portanto, como modelo a ser emulado para os séculos vindouros. Àqueles que seguirem o exemplo de Alonso, está reservado o mesmo destino glorioso. Com isso, torna-se discutível a afirmação de Endress (2005, p. 204) de que, frente à morte de Alonso, o auditório sentiria uma "buena dosis de rebeldia contra un destino injusto". Se a morte é injusta, a peça não poderia, por exemplo, assegurar o preceito do docere (ensino) horaciano. Entretanto, segundo o que dissemos, nota-se que o destino não é injusto, pois, com a morte, D. Alonso consegue o prêmio da imortalidade.

\section{El caballero de Olmedo: uma tragédia?}

Um último apontamento a ser feito diz respeito à questão genérica. García-Valdés (1994, p. 137) aponta que na Espanha do século XVII existem, sim, tragédias autênticas, embora não se ajustem "por completo a las normas clásicas y renancentistas [...]". De modo similar, Arellano (2001, p. 107) afirma que o Caballero é uma tragédia à espanhola, "pero tragedia”. Para justificar a afirmação de que o Caballero de Olmedo é uma tragédia, GarcíaValdés (1994, p. 138) se vale da morte do herói: "De El caballero de Olmedo de Lope, puede decirse otro tanto: es una verdadera tragedia, en la que el autor no huye de las sombras y nuncios, y que finaliza con la muerte, el más universal y persistente de todos los critérios para identificar una tragedia [...]". A pesquisadora universaliza uma "regra" do teatro antigo, a morte como sinônimo da tragédia, e aplica-a ao teatro espanhol do Seiscentos, esquecendo, assim, a historicidade e a contingência das práticas letradas sejam elas dos antigos gregos sejam dos modernos espanhóis. Além disso, a peça não finaliza com a morte, como já pontuado.

No capítulo XIII da Poética, Aristóteles afirma que terror e piedade são suscitados na imitação trágica por meio da representação de homens médios que devem passar da felicidade para a infelicidade. Portanto, para o Filósofo não se devem ser representados a) homens bons que passam da boa para a má fortuna, pois não suscitaria terror nem piedade, mas repugnância; 
b) homens maus que passem da infelicidade para a felicidade, pois não é de acordo com os sentimentos humanos nem suscita terror e piedade; e c) homens maus que passem da boa para a má fortuna, dado que essa situação satisfaz os sentimentos humanos e não causa terror e piedade (ARISTÓTELES, 1984, 1452b 31; 1453a).

Para o Filósofo, a tragédia deve optar por um mito simples e não por um duplo, isto é, deve prezar pela representação de um indivíduo que passa da felicidade para a infelicidade e não o inverso (ARISTÓTELES, 1984, 1453a 17). “A mais bela tragédia”, portanto, deve prezar por terminar no infortúnio (ARISTÓTELES, 1984, 1453a 22), e a esse modelo de tragédia cabe o primeiro lugar. Aristóteles coloca em segundo lugar as tragédias de dupla intriga como, por exemplo, a Odisseia, pois esta "oferece opostas soluções para os bons e para os maus" e, por isso, essas peças de dupla intrigas assemelham-se mais à comédia (ARISTÓTELES, 1984, 1453a 30).

No século XVII espanhol, esses apontamentos aristotélicos são retomados, por exemplo, por Francisco Cascales e por José António González de Salas. Cascales (2015, p. 159160) prescreve para a tragédia, a fim de mover terror e piedade, a representação de homens médios, pois: a) se os bons passam para a má fortuna, os espectadores se indignarão contra a "justicia de la tierra" porque veem que "los buenos son castigados"; ao passo que b) se os maus são castigados, a ação é tomada por "justa y buena” (CASCALES, 2015, p. 159-160) pelo auditório. Essa dupla mutação de fortuna é própria ao gênero cômico.

Na Nueva Idea de la tragedia antigua (1633), González de Salas (1778, p. 68) relembra que a comédia realiza duas mutações de fortuna, porque faz os bons passarem da infelicidade para a felicidade, e o maus da felicidade para a infelicidade. Além disso, tal movimento deleita a audiência.

No Caballero, os maus, Rodrigo e Fernando, após matarem Alonso, dirigem-se à casa de Inés. Lá D. Rodrigo, como se nada tivesse acontecido, pede a mão de Inés em casamento, e de D. Fernando pede a da irmã de Inés, Doña Leonor. Com isso, os personagens encontram-se num estado de felicidade, pois acreditam que sairiam ilesos do crime. Todavia, após a chegada de Tello e seu relato ao rei, os personagens são sentenciados à morte e, assim, passam à infelicidade. Já D. Alonso Manrique passa da infelicidade, ocasionada pela morte, à felicidade com o prêmio da imortalidade.

No Oráculo Manual y Arte de Prudencia (1647), Baltasar Gracián aponta que na casa da Fortuna há duas portas: a do prazer e a do pesar. Segundo ele, quem entra pelo do prazer, sai pelo do pesar, e, por conseguinte, quem entra pela do pesar sai pela do prazer. Por isso, o jesuíta 
afirma que os homens devem se atentar mais à felicidade da saída do que ao aplauso da entrada (GRACIÁN, 1674, p. 461). Para Gracián (1674, p. 496), a vida é como uma Comédia. Logo, os homens devem buscar bons fins.

Disto isso, podemos dizer que El caballero de Olmedo, de Lope de Vega, assemelhase mais às convenções da comédia em voga no Seiscentos do que às da tragédia. É mais oportuno pensar a peça como uma comédia do que uma tragédia “à espanhola", como defende Arellano (2001). D. Alonso entra pela porta do pesar e sai pela do prazer, passando, assim, do infortúnio à felicidade. Já seus algozes entram pela porta do prazer e saem pela do pesar, passam da felicidade à infelicidade.

\section{Considerações finais}

Evidentemente, neste artigo não objetivamos colocar a nossa interpretação como $a$ interpretação. Na verdade, buscamos interpretar e contrapor alguns estudos sobre El caballero de Olmedo, de Lope de Vega, aos estudos poéticos e retóricos. Além disso, ao historicizarmos, isto é, ao reconstruímos alguns preceitos centrais do fazer letrado espanhol em voga no século XVII, indicamos limitações nos estudos que se constituíram em torno da peça de Lope. Isso não significa que esses estudos estejam errados. Pelo contrário, o estudo de Rico (2016) é meritório no sentido de conseguir mapear possíveis fontes que deram viço ao Caballero. Contudo, Rico (2016) e os estudos que lhe seguiram se detiveram demasiadamente nestas fontes e, por isso, leram o teatro espanhol do Seiscentos à luz do teatro antigo. Esses estudos esqueceram a historicidade das práticas letradas e a diferença (o que não significa ruptura) na recepção de determinados preceitos antigos pelos preceptistas e poetas espanhóis seiscentistas. Enfim, neste artigo demonstramos que caminhos interpretativos novos sempre são possíveis. Além disso, elucidamos que, como salienta Demo (2002), frente à autoridade do argumento, não há argumento de autoridade.

\section{Referências}

ALCIATO, A. Los emblemas de Alciato traduzidos en rhimas españolas; añadidos de

figuras y de nuevos emblemas en la tercera parte de la obra. En Lyon: por Mathias Bonhome, 1549.

AGOStinho, S. A Cidade de Deus. Tradução, prefácio, nota biográfica e transcrições de J. Dias Pereira. Lisboa: Edição da Fundação Calouste Gulbenkian, 1996. Tomo I (Livro I ao VIII). 
ARELLANO, I. Estructura dramática y responsabilidad. De nuevo sobre la interpretación de $E l$ caballero de Olmedo, de Lope de Vega (notas para una síntesis). In: MOLINA, I. P.; SERRANO, A. (Eds.). En torno al teatro del Siglo de Oro: XV Jornadas de teatro del Siglo de Oro. Almeria: Instituto de Estudios Almerienses; Diputación de Almería, 2001. p. 95-113. ARISTÓTELES. Retórica. Prefácio e introdução de Manuel Alexandre Júnior/ tradução e notas de Manuel Alexandre Júnior, Paulo Farmhouse Alberto e Abel do Nascimento Pena. São Paulo: WMF Martins Fontes, 2012.

ARISTÓTELES. Poética. Tradução, comentários e índices analíticos e onomástico de Eudoro de Souza. In: . Metafísica, Ética a Nicômaco, Poética. São Paulo: Abril Cultural, 1984, p. 239-269.

CASCALES, F. Tablas poéticas. London: Classic Reprint Series, Forgotten Books, 2015.

CERVANTES, M. de. Don Quijote de la Mancha. Edición conmemorativa IV Centenario Cervantes. Madrid: Real Academia Española; Madrid: Alfaguara, 2015.

CHIAPPETTA, A. Retórica e crítica literária na Antiguidade. Phaos, Campinas, n. 1, p. 3960, 2001.

CONTATORI, G. F. O bom é premiado e o mau é castigado: a eficácia pedagógica em $\boldsymbol{E l}$ caballero de Olmedo, de Lope de Vega. A Margem: Revista Eletrônica de Ciências Humanas, Letras e Artes, Uberlândia, v. 16, n. 1, p. 7-26, 2019.

CURTIUS, E. R. Literatura europeia e Idade Média latina. Brasília: Instituto Nacional do Livro, 1979.

DEMO, P. Cuidado metodológico: signo crucial da qualidade. Sociedade e Estado, Brasília, v. 17, n. 2, p. 333-348, jul./dez. 2002.

DIONÍSIO DE HALICARNASSO. Tratado da imitação. Edição de Raul Miguel Rosado Fernandes. Lisboa: Instituto Nacional de Investigação Científica/ Centro de Estudos Clássicos das Universidades de Lisboa, 1986.

DRYDEN, J. An Essay of Dramatic Poesy. In:___. The dramatick Works of John Dryden, Esq; in six volumenes. London: Printed for J. Tonson and Sold by R. Knaplock, W. Taylor, W. Mears, J. Browne, W. Churchill, E. Symon, and J. Brotherton, 1717. v.1, p. 15-83. ENDRESS, H.P. La creación de una obra maestra: El Caballero de Olmedo. Una tentativa de reconstrucción. In: CLOSE, A (Ed.). Edad de oro cantabrigense: actas del VII Congreso de la Asociación Internacional de Hispanistas del Siglo de Oro, 2006. p. 201-205. 
GARCÍA-VALDÉS, C. C. El caballero de Olmedo: tragédia y parodia. In: ARELLANO, I.; GARCÍA-RUIZ, V.; VITSE, M. (Eds.). Del horror a la risa: los géneros dramáticos clásicos. Navarra. Universidad de Navarra / Edition Reichenberger Kassel, 1994. p. 137-160.

GONZÁLEZ DE SALAS, J. A. Nueva ideia de la tragedia antigua o ilustración ultima al libro singular de Poetica de Aristoteles Stagirita. En Madrid: Por D. Antonio de Sancha, 1778.

GRACIÁN, B. Agudeza y arte de ingenio. Introdução de Jorge M.Ayala; edição e notas de Ceferino Peralta, Jorge M. Ayala e José M. Andreu. Zaragoza: Prensas Universitarias de Zaragoza: Departamento de Educación, Cultura e Deporte del Gobierno de Aragón; Huesca: Instituto de Estudios Altoaragoneses, 2004.

GRACIÁN, B. Oraculo Manual y Arte de Prudencia sacada de los aforismos que se discurren en las obras de Lorenço Gracián. In: . Obras de Lorenzo Gracián: Tomo Primero que contiene El criticón (primera, segunda y tercera parte), El oráculo y El Heróe. Ultima impressión mas corregida, y enriquecida de Tablas. En Madrid: En la Imprenta de la Santa Cruzada, 1674, p. 449-513.

GRIMAL, P. Diccionario de mitologia griega y romana. Prefácio de Charles Picard; prólogo da edição espanhola de Pedro Pericay. Barcelona, Buenos Aires, México: Ediciones Paidos, 1979.

HANSEN, J. A. O que é um livro?. Cotia, SP: Ateliê Editorial; São Paulo: Edições SESC São Paulo, 2019.

HORÁCIO. Arte Poética. intr., trad. e com. de R. M. Rosado Fernandes. Lisboa: Mem Martins: Inquérito, 1984.

LONGINO. Do sublime. In: ARISTÓTELES; HORÁCIO; LONGINO. A poética clássica. Introdução Roberto de Oliveira Brandão; tradução Jaime Bruna. São Paulo: Cultrix, 2014. p. 69-114.

LOPE DE VEGA, F. El Caballero de Olmedo. Ed. Francisco Rico. Madrid: Catedra/ Letras Hispánicas, 2016.

OLIVEIRA, E. A. V. de. El Caballero de Olmedo: razão e paixão; amor e morte no século de ouro espanhol. Hispanista, s/l, v. 15, n. 58, p. s/n, 2014.

PÉCORA, A. À guisa de manifesto. In: Máquina dos gêneros: novamente descoberta e aplicada a Castiglione, Della Casa, Nóbrega, Camões, Vieira, La Rochefoucauld, Gonzaga, Silva Alvarenga e Bocage. São Paulo/ Campinas: Editora da Universidade de São Paulo/ Editora da Unicamp, 2018, p. 11-16. 
PINCIANO, A. L. Philosophía antigua poética. Edição de José Rico Verdú. Biblioteca Castro, 1998.

QUEVEDO, F. de. La cuna y la sepultura: para el conocimiento proprio, y desengaño de las cosas agenas. In: . Obras de Don Francisco de Quevedo Villegas: segunda parte. En Brusselas: De la Emprenta de Francisco Foppens, Impressor y Mercader de Libros, 1670, p. 195-232.

RICO, F. Introducción. In: LOPE DE VEGA, F. El caballero de Olmedo. $26^{\mathrm{a}}$ ed. Madrid: Catedra/Letras Hispánicas, 2016. p. 11-95.

ROSADO FERNADES, R. M. Introdução. In: DIONÍSIO DE HALICARNASSO. Tratado da imitação. Edição de Raul Miguel Rosado Fernandes. Lisboa: Instituto Nacional de Investigação Científica/ Centro de Estudos Clássicos das Universidades de Lisboa, 1986. p. 11-30.

RYNGAERT, J.P. Introdução à análise do teatro. São Paulo: Martins Fontes, 1996.

SÉNECA. De la brevedad de la vida. In: Tratados morales. Edición Pedro Rodríguez Santidrián; traducción Pedro Fernández Navarrete. Madrid: Editorial Espasa Calpe, 2005, p. 155-185.

VIEIRA, A. Sermões de quarta-feira de cinza. Organização Alcir Pécora. Campinas (SP): Editora da Unicamp, 2016. 